Revista Iberoamericana, Vol. LXXVIII, Núm. 241, Octubre-Diciembre 2012, 769-781

\title{
LA BONDADOSA NATURALEZA Y LA GEOGRAFÍA GUATEMALTECA: EL MODELO FUNDACIONAL DE LA RECORDACIÓN FLORIDA
}

\author{
POR \\ JoRge CHEN SHAM \\ Universidad de Costa Rica
}

En su sugestivo libro La patria del criollo, Severo Martínez Peláez no sólo analiza el surgimiento de la conciencia “criolla” en la Capitanía General de Guatemala con esa reivindicación de los nacidos en tierras americanas para gobernar y administrar las tierras que, por el derecho de sus mayores, habían ganado, sino también plantea que la Recordación florida: Discurso historial, natural, material, militar y político de Reyno de Guatemala (1690), escrita por el guatemalteco Francisco Antonio de Fuentes y Guzmán (1642-1699), desarrolla esa expresión de esa conciencia “criolla”, en donde la geografía guatemalteca es exaltada de una manera diferencial, pues es "la alabanza y la defensa de la patria-patrimonio, y lo que debemos hacer es descubrir el significado del peculiar tratamiento que en ella se hace de tierra” (Martínez Peláez 133). Tal y como expone Martínez Peláez, se esboza una nueva sensibilidad que nos permitirá ver la función del viaje en unos términos muy diferentes al modelo cronístico basado en la visión de los europeos, conquistadores o misioneros.

La tradición hispánica ofreceestemodelo sancionado por el proceso de descubrimiento y conquista del Nuevo Mundo, en donde la crónica permite al enunciatario situarse como historiador o cronista (cuando fuese testigo ocular) dentro de un viaje que se concibe como periplo simbólico, misionero o de expedición militar, por cuanto temáticamente se plantea como correlato del proceso de sujeción ideológica y territorial de las nuevas tierras anexadas a la corona española. Es decir, en la crónica colonial se concibe el viaje como parte de ese proceso de descubrimiento/conquista y, por lo tanto, dentro de un contexto de expansión bélica y de dominio ideológico. En primer lugar, ese viaje que realiza el cronista se realiza por motivos militares o religiosos, en donde se trata de aprehender una realidad distante, lejano o exótica (Lafarga); criterio muy común que utiliza el cronista o el misionero español cuando describe la realidad americana.

Por el contrario, Beatriz González-Stephan nos recuerda que una nueva sensibilidad hacia el espacio americano se puede encontrar esbozada en las crónicas escritas por criollos americanos, en donde la invención de América pasa irremediablemente por una indagación que obliga a reconfigurar su pasado y su presente (38) e inscribirse 
“para validar su propio hábitat como locus enunciativo” (42). Lo interesante es que tal posición la encontremos ya planteada en la Recordación florida al final del siglo XVII. La posición de Fuentes y Guzmán presenta una marcada cercanía y emotividad al describir las tierras de la provincia de Guatemala. Para tal finalidad, nos detendremos en el Libro 8 de la Recordación florida, en donde el cronista se dedica por completo a narrar su periplo geográfico por el Valle de Guatemala, mientras que en el Libro 9 "se extiende en semicírculo hacia el oriente, abarcando norte y sur de la ciudad (Mesas, Petapa, Amatitlán, volcanes)” (Sáenz xxxi, nota 79). En estos libros de la Primera Parte de la Recordación florida, se pondera positivamente lo que denominaríamos como una "historia natural" de la zona central de Guatemala, lo que él llama el "Valle de Goathemala” y lugares circunvecinos.

El recuento de la geografía guatemalteca comienza: a) con el establecimiento de un inventario del patrimonio natural y civil de cada región; y b) con la finalidad de propiciar un estudio de sus elementos más característicos dentro de ese afán de curiosidad erudito-científica. La observación y la reflexión serán los dos principios que guían la utilidad del viaje. Tal empresa requiere de una capacidad de juicio y de meditación que deben acompañar las observaciones del cronista. He aquí la diferencia de capacidad para juzgar que posee Fuentes y Guzmán, pues su “diligencia” a la hora de observar e inventariar nos descubre una perspectiva diferente que anima las etapas de la recolección y del acomodo de los datos, desde la observación a su procesamiento; se trata del amor hacia su "patria” (en tanto lugar en donde se nace) o lo que Martínez Peláez explicaba como "la actitud del criollo hacia la tierra" (134). Con Fuentes y Guzmán, tal y como podríamos encontrar en la conciencia criolla, se rechaza la banalidad y la futilidad en los objetivos del viajero cuando sus observaciones no se acompañen de una razón práctica, el enaltecimiento de su "patria” y lo que es aún todavía grave, cuando la finalidad del viajero radique únicamente en un interés personal de un viaje por intereses personales y poco sistemático. ${ }^{1}$ Mostrar la realidad guatemalteca para reivindicar el derecho de ensalzar su "patria” es la tarea de justicia y de verdad que se propone, como objetivo del libro, Fuentes y Guzmán en la carta-epístola “Al lector”:

Motivos fueron, para emprender este no despreciable ni ligero trabajo, la consideración atentamente cariñosa á mi patria, de que, siendo en la circunvalación de su reino de 1.700 leguas de tierra, prolíficamente fecunda y estimablemente rica en minerales y

\footnotetext{
1 Es lo que se denomina en la mentalidad del siglo xvIII ilustrado como la utilidad del "viaje”; véase lo que apunta Gaspar de Jovellanos, casi un siglo más tarde (1781), en su "Discurso dirigido a la Real Sociedad de Amigos de Asturias, sobre los medios de promover la felicidad de aquel principado": "Para conocer la situacion de una provincia no basta haber vivido en ella largo tiempo [...]. Tampoco basta haberle recorrido de un cabo al otro, si esto no se hizo inquiriendo, observando y apuntando lo más notable. El que viaje solo por divertirse, el que atr[a]viese muchas veces un país sin más objeto que el de atender a sus particulares negocios, sólo podrá decir lo que ha visto” (442).
}

Revista Iberoamericana, Vol. LXXVIII, Núm. 241, Octubre-Diciembre 2012, $769-781$
ISSN 0034-9631 (Impreso) 
preciosísimos frutos, hayan los autores y cronistas de Indias gastado tan poco papel y tan pocos renglones en describir sus maravillas. (57)

Más allá de la captatio benevolentiae, se dibuja aquí esa noción de utilidad, que tanta importancia alcanzará en los viajes ilustrados, pues el afán de reivindicar lo autóctono -por motivos afectivos e ideológicos de reivindicar su patrimonio discursivo y de sangre ante la Corona española, como se he analizado en otro lugar (Chen 138139)-,“[d]esborda la acepción puramente económica, para convertirse en expresión de un modo de estimar los bienes de la sociedad” (Maravall, "Espítiru” 301). De esta manera, si el viaje es el motor de conocimiento del estado del país, la utilidad del viaje que se emprenda se mide por esa vinculación que enuncia un ligamen a una tierra y a una conciencia de pertenencia identitaria.

En las crónicas americanas escritas ya en pleno siglo xvIII por criollos americanos, Beatriz González-Stephan encuentra consolidado esta conciencia reivindicativa; las realidades históricas y el ligamen con la metrópoli impondrán, plantea ella, un espíritu crítico y una mentalidad diferenciada en unas nuevas élites coloniales con poder económico, ligamen territorial y acumulación simbólica, lo cual los condujo a “exaltar el saber y la erudición [de este continente] como patrimonio de la misma calidad que la posesión de bienes materiales” (González-Stephan 46). En este sentido la Recordación florida inaugura a finales del siglo xvII esta "expresión americana” y servirá de modelo fundador desde nuestra perspectiva. La visión rústica de los pueblos que componen esta zona no sólo se describe bajo el tópico del locus amoenus de la bucólica, sino de la hiperbolización que la crónica colonial configura bajo la representación de "un mundo que se autogenera basado en la proliferación y la mezcla [de la abundancia]" (Rodríguez Cascante 66). Veamos la imagen de conjunto y la descripción de las distintas regiones que conforman el Valle Central de Guatemala:

[...] son, el de Chimaltenango, de saludable temperamento y alegre cielo; el abundante y próvido Jilotepeque; el fecundo y elevado de Canales; el dilatado y numeroso de pueblo de Sacatapeques; el alegre y saludable de Mixco; el de las Mesas, más inmediato y no menos fértil que los otros; el de las Vacas, y valle de Alotenango; que todos juntos, por la abundancia, diversidad y gustosa sazón de sus frutos, hacen y ordenan la ordinaria despensa y providente granero de Goathemala: prerrogativa y singular calidad que le da el primer lugar entre las más deleitosas tierras del Reino; gozando las más bellas y espaciosas campiñas, de quienes no se conocen si rinden más copioso fruto con los sazonados pastos ó con las más maduras mieses. (Fuentes 215)

La naturaleza pródiga que ofrece sus frutos a los hombres, propia del tópico de la Edad de Oro, se alía aquí a una estrategia que pondera los recursos de la explotación de la tierra. El discurso ilustrado considera la agricultura como "una función vital que determina la pervivencia de una sociedad y para garantizarla debe haber formas sociales

Revista Iberoamericana, Vol. LXXVIII, Núm. 241, Octubre-Diciembre 2012, 769-781 ISSN 0034-9631 (Impreso) ISSN 2154-4794 (Electrónico) 
y culturales que la defiendan, que aseguren su reproducción” (Kaempfer 354). Pero para llegar a este aserto que hace de la agricultura la primera fuente de la riqueza y de la felicidad de una sociedad dentro de una mentalidad más bien del último tercio del siglo xvIII, el discurso de la agricultura pondera la representación de una naturaleza hospitalaria (lo contrario de lo que ponderará las crónicas al plantear un clima insaluble y una selva indómita contra la cual debe luchar el ser humano), bajo rasgos propios del modelo de la Arcadia grecolatina y su transmisión en la poesía bucólica renacentista (De la Flor 135). Esta exaltación y recuperación de la vida del campo tendrá su base en el trabajo agrícola y en los ciclos de las estaciones, para los cuales hay un acoplamiento perfecto entre las labores agrícolas y los ciclos de las cosechas (Dorca 15-16), mientras que se le elimina el elemento fatigoso a las faenas de la tierra para presentarlas, más bien, en un ambiente festivo y placentero. He aquí como la concepción de la agricultura se ajusta a esta representación de una bondadosa naturaleza, con lo cual el ser humano sostiene una especie de idilio, de relación armónica, gracias a la cual la tierra da sin "fatiga” sus frutos. El cuadro que nos pinta Fuentes y Guzmán, en este inicio de capítulo, continúa el elogio de la fecundidad de la tierra con una naturaleza, fuerte y podrosa, pródiga y abundante (Cros 282):

\begin{abstract}
No siendo menos rico y adornado su alegre y desenfadado territorio de verdes selvas y tupidas breñas, que favorecido y bañado de nobles ríos, copiosas fuentes y aguas minerales que brollan en sus cristalinas y saludables linfas, siempre calientes y nunca destempladas; y mucho más, no careciendo el curso de muchos nobles, abundantes ríos de regalada y copiosa pesca, como sus frescas, umbrosas, verdes selvas de entretenida y provechosa caza; viéndose ennoblecidos los pueblos de suntuosos y ricos templos y de conventos no menos magníficos que acomodados [...]. (Fuentes 215)
\end{abstract}

Tal y como insiste Rodríguez Cascante, el despliegue de una retórica que sirve para elogiar sobre la base de una amplificatio adjetival, tiene la función ideológica de mostrar al destinatario metropolitano de la crónica, tanto una defensa del patrimonio así como una reivindicación del espacio americano (71); pero ello conduce, bajo el tópico elaborado, a una representación de la fecundidad de las diferentes zonas orográficas (montaña, valles, campos, ríos ) y de la abundancia de los recursos naturales (agricultura, minería, pesca, ganadería) que cae en la visión utópica. Los dones de la tierra contribuyen también a la riqueza y a la prosperidad de los seres humanos ("los pueblos de suntuosos y ricos templos y de conventos”), como si fuera la consecuencia directa e inmediata de la naturaleza pródiga; es decir, se trata de su intervención benefactora sobre la actividad humana, con lo cual nos lleva luego a exaltar el trabajo de los indios:

Son los indios paisanos destos valles descasadamente ricos, y jamás por su actividad y laboriosa frecuencia necesitados. Son todos uniformemente bien proporcionados en la

\footnotetext{
Revista Iberoamericana, Vol. LXXVIII, Núm. 241, Octubre-Diciembre 2012, 769-781 ISSN 0034-9631 (Impreso) ISSN 2154-4794 (Electrónico)
} 
formación de sus cuerpos, fáciles y voltarios de natural, aunque domésticos y dóciles. Generalmente hábiles y sumamente industriosos en todo género de arte; conservan con tenacidad cuidadosa su propio antiguo uso, y así, ni más ni menos, en todo aquello que establecieron ó dejaron erigido sus mayores, aunque reconozcan ser contra el adorno y uso político. (Fuentes 216)

Contrasta este retrato de los indígenas con la imagen que nos presentaban las crónicas europeas, sobre todo a partir de las comentarios que el Conde de Buffon y Cornelius de Pauw esgrimían sobre la naturaleza desarreglada del indígena americano, en esa consonancia entre clima, ambiente y sus repercusiones en un modelo racial, tal y como veremos más adelante. Sin embargo, lo que me interesa destacar aquí es ese clima de virtud y de trabajo con arreglo a la naturaleza pródiga que se describe en esta cita, pues corresponde a la pintura de un estado social en el que reina el esfuerzo y el trabajo, acorde a esta naturaleza pródiga y abundante.

En este sentido, continúa Fuentes y Guzmán ese recorrido por los valles de Guatemala, señalando ciertas especificidades orográficas por supuesto, además de curiosidades eruditas para que el lector tenga información de primera mano. Por ejemplo, en el Valle de las Mesas, el rasgo de la fecundidad entra en correlación con la "monumentalidad” de los hallazgos hechos en esta tierra; la toponimia se justifica aquí, por lo cual los vestigios del pasado son una prueba de la excepcionalidad del territorio descrito: "Y el conocido renombre de las Mesas le viene de las lisas y iguales llanuras de que se compone el valle; en cuyos dilatados, amenos campos, en tiempo de las aradas de la tierra, se han descubierto desmesurados y crecidos huesos de gigantes” (225). Y termina calificando este valle haciendo énfasis en esa excepcionalidad que se transforma en característica particularizante del territorio:

En este estimable, maravilloso valle, como el granero general, por la copia de maices que abundantemente distribuye y copiosamente comunica á la ciudad de Goathemala [...], como si fuera inagotable, porque las unas colmadas y anundantes cosechas alcanzan sobradas á las otras. (226)

Podríamos pensar que se trata de un cliché a la hora de describir el espacio guatemalteco, de manera que las notaciones orográficas y de geografía humana se repiten con cada valle y población observados. Así en el capítulo 5, Libro 9, la región de Amatitlán también se resalta en los mismos términos; la ponderación excesiva y laudativa ahora del clima permite la explotación agrícola y la vida sana y tranquila: “[...] sito en este excelente valle, el pueblo de San Juan Amatitlán, de numeroso pueblo, de feraz y abundante territorio, excelente y templado temperamento, recreables salidas y alegre y saludable cielo, con vientos sanos y desenfadada formación de su material aspecto" (247). Ubicada en zona intermedia, este valle no es nada inhóspito; su orografía y clima

\footnotetext{
Revista Iberoamericana, Vol. LXXVIII, Núm. 241, Octubre-Diciembre 2012, 769-781 ISSN 0034-9631 (Impreso)

ISSN 2154-4794 (Electrónico)
} 
son beneficiosos y bondadodos al hombre y a la vegetación que regala al ser humano sus frutos como si fueran dones:

\begin{abstract}
Abunda esta alegre población de sazonada y copiosa variedad de frutas [...], por ser éste de temperamento medio, templado, igual y proporcionadamente entre caliente y frío, y produciendo la jugosa y pingüe naturaleza de su terreno limas y naranjas agras [sic] y dulces, piñas, sapotes, nísperos, plátanos, nanches, jinicuiles, coyoles, pitahayas, pijícaros, papayas [...] (247)
\end{abstract}

La lista continúa y la enumeración es copiosa de frutos y verduras que hacen pensar al hortus paradisíaco de la tradición clásica grecolatina, sólo que aquí se actualiza en el espacio americano. Fuentes y Guzmán pondera las variedades de maíz y los usos que se le otorga para hacer alimentos como el "atole”, el "istatatole” (atole blanco), el "jacotole” (atole agrio), el "chilatole” (de maíz y chile), así como el uso medicinal dado a algunas de estas recetas, por ejemplo, el "tlamizatole”, monstrándonos su conocimiento más integral de la realidad y de las costumbres de los habitantes de estos valles: “[...] esta bebida, á mayor operación, se toma caliente, y extiende y dilata su virtud á los efectos de excitar la naturaleza á la Venus, mueve y provoca á la orina, y facilita y hace bajar el menstruo á las mujeres que padecen retención de esta ordinaria evacuación” (228). La variedad de usos y recetas del maíz nos demuestran, por otra parte, la abundancia y la industriosidad de las habitantes de estas tierras, que han sabido utilizar plantas y animales en usos tan variados. La curiosidad se acompaña de la extrañeza frente a los usos tan distintos e inauditos en la explotación de la naturaleza; dos ejemplos llaman la atención en el capítulo 1 de este Libro 9. En primer lugar, su comentario se dirige hacia el tamaño de los saltamontés o grillos que se encuentra en estas tierras, a saber, el chapulín: "Pero entre todas cuantas extrañas y prodigiosas maravillas se experimentan, lo es, sin comparación, mayor y casi increíble, la de el Chapuli verde, que es cierta especie de langosta, cuya corpulencia ó tamaño casi llega á la longitud de un jeme” (229). Lo interesante de su recuento es lo que realizan los indígenas con estos chapulines, los abren y sus tripas se siembran para producir, ¡oh maravilla de la naturaleza!, una calabaza. El relato continúa de la siguiente manera:

[...]producen maravillosamente una mata, como la de la calabaza, quelleva por precioso y estimable fruto unos calabacitos amarillos y sumamente lustruosos á semejanza del oro; pero sembrando la pepita de estos calabacitos, los produce mucho mayores á cada vez que se siembran. (229)

Dentro de este inventario de “maravillas”, Fuentes y Guzmán describe una de las aves más peculiares del territorio americano, el colibrí al que se le denomina "admirable y prodigiosa avecita” (230). Fuentes y Guzmán subraya, al contrario, su pequenísimo tamaño y su vuelo rápido y difícil de observar a los ojos humanos:

Revista Iberoamericana, Vol. LXXVIII, Núm. 241, Octubre-Diciembre 2012, $769-781$
ISSN 0034-9631 (Impreso) 
No menos singular y maravilloso prodigio de la naturaleza, ante sí muy digno de la contemplación humana y lleno de misterio, lo que se admira en el pajarillo que es conocido en este Reino con el nombre de Gorrión, y en el imperial de México con el de Huitzitzilin, que se viste de sutiles y tornasoladas plumas de color verde, con cambiantes de oro, que hace á él movimiento de su rápido y susurrante vuelo apacibles y maravillosos tornasoles. (230)

Estamos ante la mirada absorta y maravillada del viajero. Pero no se trata, en los dos casos, del concepto de lo maravilloso ligado a la extrañeza y a la desproporción o desarreglo de América con respecto al orden eurocéntrico, según encontramos en el discurso cronístico eurocéntrico bajo el tópico del mundo al revés que domina; todo lo contrario, el prodigio de la naturaleza es lo que admira, absorto, Fuentes y Guzmán. Entonces, a la luz de lo anterior, en el esquema utilizado en la Recordación florida, se impone una determinada gramática para analizar el espacio guatemalteco, con las siguientes reglas discursivas:

a) La productividad de la tierra conduce al elogio de la agricultura y a la visión arcádica del campo. En el Cap.3 del Libro 9, se hace una descripción del Valle de las Mesas de Petapa de la siguiente manera: se cataloga como una tierra de promisión y de abundancia con labradíos, molinos de trigo, ingenios de caña de azúcar, para terminar de nuevo en un balance de su prodigalidad:

Goza [...] de saludables y templados vientos, de dulces y ligeras aguas, abundantes y varias frutas, sazonados y copiosos mantenimientos, dilatados y alegres prados, con muchas hierbas medicinales, copiosas y entretenidas pesquerías, mucha y generosa crianza de yeguas de buena raza; abundante la próvida feracidad de su terreno de copiosos y sazonados granos de trigo, rubio y tremesino, maíz, frisoles y chile el más suave, fragrante [sic] y de menos mordacidad de cuanto se produce y cría. (236)

b) Frente a la naturaleza pródiga, la explotación de la tierra en la ganadería o la agricultura no son empresas que sean arduas y difíciles para el ser humano, de manera que a la abundancia de la tierra se corresponde la bonanza y la "industria"” del que la trabaja. Por esa razón, los indios son hábiles para la agricultura ${ }^{3}$ y lo pueden hacer hasta en terrenos montañosos y poco accesibles:

2 La noción de industria que manejo aquí es la propia del Antiguo Régimen, es decir, la de ingenio y esfuerzo intelectual.

3 De ahí el elogio a la virtud y al trabajo del indio: "Laboriosamente industriosos se mantienen y conservan los naturales de este pueblo, de la frecuente aplicación y continuado trabajo de sus personas; ejercitando el arte de la rústica carpintería en arados, bieldos, palas, carros y otros instrumentos pertenecientes á la siembra y cogida del trigo, y manejando juntamente el arado y el bieldo con gran destreza en las labores circunvecinas" (238).

Revista Iberoamericana, Vol. LXXVIII, Núm. 241, Octubre-Diciembre 2012, 769-781
ISSN 2154-4794 (Electrónico) 
[...] de la profunda y maravillosa laguna que llaman de Amatitlán y Petapa, obtienen los indios petapanecos provechosas y seguras huertas de innumerables y deliciosos platanales, y eras dilatadas y de cuidadoso cultivo, atento á la producción de crecidos y excelentes melones tan buenos como los de Tierra firme en su corpulencia, fragrancia y gusto, así como las sandías crecidísimas y abundantes [...]. (236)

c) Cuando viene el caso, compara para mostrar las diferencias en relación con la metrópoli: "La varia, matizada abundancia de admirables y pulidas flores es en este alegre país con exceso crecida, aunque casi todas de las singulares y extrañas para la Europa [...]” (236). Obsérvese cómo las diferencias de la flora americana con arreglo a la europea no se plantean en términos de lo extraño; síntoma de ese enaltecimiento de lo propio, que es la base de la nueva mentidad del criollo en proceso.

d) La excepcionalidad o las características únicas de la flora se ponderan por sus usos y aplicaciones, de manera que están al servicio de la técnica y de la medicina. El límite de la utilidad es lo que hace aceptable y meritorio nuestro patrimonio botánico, como analiza Fuentes y Guzmán en el capítulo 4, Libro 9. Él hace un recuento de la cantidad de hierbas medicinales, a causa de "la calidad excelentemente medicinal de algunas maravillosas y útiles hierbas que produce, para común beneficio de los hombres” (239). Podría obedecer este inventario de plantas medicinales y de otros tipos a la necesidad de matizar lo distinto y lo diferente a los ojos de la curiosidad del lector europeo, que no las conoce; pero eso sería solamente abordar una arista de esta problemática, pues ese elogio en describir corresponde también a un prurito epistemológico, adelantándose ya a esa práctica científica del s. XviII: "This kind of pharmaceutical survey of curious yet useful and marketable flora anticipates the late eighteenth-century 'applied economic botany' and institucionalization of science” (Ewalt 16). ${ }^{4}$ Así, la Recordación florida inaugura ese modelo que se impondrá para exaltar la naturaleza americana, con esa conciencia propia del criollo. Pero esta visión enjundiosa, que se desprende de la fascinación ante los prodigios de la naturaleza, desemboca en lo que Nancy Calvo y Rodolfo Pastore denominan como "una intencionalidad natural positiva" (37), la cual revela un orden superior proclive al progreso y a la felicidad a los que aspira el ser humano. Se trata de una naturaleza pródiga, unos secretos de las plantas y flores para uso terapéutico, que hablan de la calidad de estas tierras, de aguas de ríos con propiedades curativas como las del río Pepescas: “[...] bebiéndolas y bañándose en ellas por algún tiempo, deshace con

${ }_{4}$ Ewalt analiza la crónica del jesuita José Gumilla, cuyo título sumario es el siguiente: El Orinoco ilustrado, y defendido, historia natural, civil y geographica de este gran río, y de sus caudalosas vertientes; govierno, usos, y costumbres de los Indios sus habilitadores, con nuevas, y utiles noticias de animales, arboles, frutos, aceytes, resinas, yerbas, y raíces medicinales (1745). De manera que este inventario de recursos naturales y técnicos no es parte de una gramática para representar el territorio americano en su diversidad y grandeza.

ISSN 2154-4794 (Electrónico)
ISSN 0034-9631 (Impreso) 
suavidad insensible y efecto milagroso un género de tumor que se hace ordiariamente á las mujeres en las gargantas, que llaman los médicos bocio" (Recordación 249). ${ }^{5}$

Ahora bien, pintar como ilimitadas las riquezas de este "país" hasta hacerlo un rasgo de la abundancia se encontraba ya en el discurso cronístico desde las Cartas de relación de Hernán Cortés, sobre todo la Carta II, ${ }^{6}$ en donde se describe la riqueza, la magnificencia del imperio azteca y de la ciudad de Tenochtitlán:

Hay en esta gran ciudad muchas casas muy buenas y muy grandes, y la causa de haber tantas casas principales es que todos los señores de la tierra vasallos de dicho Muteczuma tienen sus casas en la dicha ciudad [...]; e demás de esto, hay en ellas muchos ciudadanos ricos, que tienen asimismo muy buenas casas. Todos ellos, demás de tener muy buenos y grandes aposentamientos, tiene muy gentiles vergeles de flores de diversas maneras. [...]

Hay en todos los mercados y lugares públicos de la ciudad, todos los días, muchas personas trabajadoras y maestros de todos los oficios [...]. La gente desta ciudad es de más manera y primor en su vestido y servicio que no la otra destas otras provincias y ciudades [...]. Y por no ser más prolijo en la relación de las cosas deste gran ciudad (aunque no acabaría tan aína) no quiero decir más sino que en su servicio y trato de la gente della hay la manera casi de vivir que en España, y con tanto concierto y orden como allá, y que considerando esta gente ser bárbara y tan apartada del conocimiento de Dios y de la comunicación de otras naciones de razón, es cosa admirable ver la que tienen en todas las cosas. (68-69)

La cita es muy larga pero necesaria para comprender esa admiración y asombro que encontró Cortés en la capital del imperio azteca. La riqueza y ostentación, el comercio y la agricultura, el sentido de "policía"; es decir, de las normas de la convivencia social y del refinamiento de la civis, todo ello asombra al conquistador español, de tal modo de que no sabe y no se puede explicar cómo un pueblo gentil (bárbaro y no racional) pueda tener tal boato, organización y riqueza. Por lo tanto, la abundancia “americana”es un rasgo retórico desde las crónicas coloniales para aprehender el espacio americano. Pero la nueva función ideológica que le proporciona el criollo Fuentes a este mismo rasgo varía, está al servicio de su elogio particularizante y del concepto de "patria”,

5 Muy diferente esta actitud, tal y como se desarrolla en las expediciones europeas del s. XVIII, en las que el inventario de la botánica y de otros recursos naturales estaban al servicio de "políticas imperiales y coloniales" (Nieto 18), no se presenta en la Recordación florida (lo cual es un indicio de que es una crónica de transición) las taxonomías. Eso es propio del ese espíritu crítico dieciochesco, el cual desemboca en un proceso de traducción y legitimación de lo americano bajo la idea de uniformidad y razón, sobre todo en lo que se refiere a las plantas beneficiosas y a sus componentes químicos.

6 Para el caso de la Recordación florida, ya Rodríguez Cascante (2004) analiza esta retórica de la abundancia desde el punto de vista sintáctico-morfológico, por medio de la adjetivación, la enumeración y de las abundantes cláusulas subordinadas. Tal y como señala este crítico, el que desarrolla este tópico de la abundancia en el contexto hispanoamericano es Julio Ortega.

ISSN 0034-9631 (Impreso) 
como vimos más arriba. Es más, la “admiración” por la civilización maya, no tiene la misma función que en el Cortés maravillado por el lujo y el derroche de la corte azteca o la vida un poco disoluta de Montezuma, los cuales le causaron su caída (Merriman 92). Recordemos que al inicio de su crónica, Fuentes y Guzmán inaugura su relato con un elemento muy propio de la historia civil (moral) de los pueblos, como sería hacer la historia del imperio maya. Con ello, se establece la continuidad histórica y el legado que la antigua civilización maya ha producido en tierras de la Capitanía General de Guatemala. Este vínculo se desarrolla en términos de un patrimonio familiar e histórico del que Fuentes y Guzmán se enorgullece y elogia en los inicios de la Recordación florida (Chen 130-131), recordando que él proviene de una dinastía de conquistadores, la que con Bernal Díaz del Castilló conquistó y fundó un nuevo imperio en el Nuevo Mundo sobre las bases de uno anterior en lo que denomina la lógica de la continuidad de la translatio imperii.

Pero volviendo al caso específico de la abundancia del territorio, a ello contribuye también el retrato del indígena guatemalteco como hacendoso, trabajador y virtuoso, el cual vive ordenamente y en paz en sus pueblos y en las haciendas en las que ellos son la mano de obra indispensable. En este sentido, Fuentes y Guzmán hace una descripción de las costumbres que él ha observados en los indios de estos valles al momento en que escribe; elogia sus tratos familiares, los pondera como buenos cristianos que guardan las fiestas religiosas, lo cual contrasta con lo que plantean las crónicas escritas por los misioneros en esa ponderación de que practicaban sus ritos de "gentilidad", además de que se les acusaba de ebrios y vagos; todo lo contrario realiza Fuentes y Guzmán y se extraña de tales ataques, aunque por supuesto, en buena ortodoxia religiosa rechace los cultos indígenas y sus monumentos erigidos (Méndez 38):

[...] no sé que haya nación que observe y estile la costumbre que en esta de los indios se vió y conservó desde el tiempo de su gentilidad, observando hasta hoy muchas torpezas de aquellos tiempos, en que sólo se entregaban á la gula, embriaguez y deshonestidades; porque lo que hoy se practica es [otra cosa]. (Fuentes 216)

De manera que los presenta como buenos y dóciles siguiendo el modelo del buen salvaje; crían a sus hijos con una educación en la que fortalecen su cuerpo y espíritu, enseñándoles a los hijos la caza, la pesca, la labranza; mientras que a las hijas les inculcan los oficios del hogar, el maíz y el tejido (221). La naturaleza bondadosa y la fiereza del indio ahora están al servicio de una concepción armoniosa de la sociedad por un lado $\mathrm{y}$, por otro, con arreglo a ese programa que impone el trabajo y la virtud como ideal de estos "hombres naturales", muy propio del ideal del salvaje bondadoso e ingenuo. A ello corresponde esa manera tan particular de comenzar su crónica Fuentes y Guzmán, pues la empieza como historia civil que se remonta a la civilización maya, haciendo hincapié en sus templos y monumentos y, de esta manera, no propone la visión actual

\footnotetext{
Revista Iberoamericana, Vol. LXXVIII, Núm. 241, Octubre-Diciembre 2012, 769-781 ISSN 0034-9631 (Impreso) ISSN 2154-4794 (Electrónico)
} 
de una Guatemala civilizada o que estaría dentro de ese ciclo de las civilizaciones, con su magnificencia y sus recursos naturales. Esto significa ese punto de inflexión que reivindica, por un lado, el recordatorio de los que habitaron primeramente este espacio guatemalteco privilegiado; y por otro, muestra la transmisión y la línea de continuidad que indaga la utilidad de la educación civil-intelectual y moral de la crónica, en tanto esos indios, mediante su trabajo y progreso, y principalmente los criollos, quienes tienen actualmente la posesión de fincas, haciendas, ingenios de azúcar. Por lo tanto, da continuidad a ese esplendor de antaño y a ese manejo de la agricultura y ganadería, de la artesanía y explotación de bosques y frutos, de los antiguos habitantes de Guatemala a los que la moran y trabajan hoy en día.

En conclusión, acudir a la información del contexto arqueológico para comprender la manera en que se plantea la organización y la estructura de la Guatemala del siglo XVII, ver en los indios y en su trabajo una fuente de riqueza, plantear la abundancia de un territorio antes explotado por otros y ahora en sus manos (de los criollos), son las causas necesarias para fundamentar esa imagen de armonía y, por lo tanto, de continuidad gracias a las cuales la tierra, pródiga y hospitalaria, sigue dando sus dones a los seres humanos. Por otra parte, no se podría negar estas circunstancias de una realidad guatemalteca con un sustrato indígena evidente y fundamental; valorar las destrezas del trabajo manual y las cualidades del indígena son argumentos que pesan en esa relación entre población y la geografía, la ocupación de las sierras y valles en el uso del espacio por grupos humanos (Verdesio 67).

A la luz de lo anterior, "la relación que se da entre medio ambiente y ser humano o [...] entre asentamiento y sistemas de producción de alimentos" (Vedesio 67) justifica la abundancia de población, recursos naturales a su disposición, y solamente de esa manera puede comprenderse dentro de la nueva realidad que se impone en América. La explotación natural con valor económico y el despliegue de las enumerables ventajas de la agricultura y de la flora y fauna autóctonas son de gran utilidad para comprender la economía de explotación de Guatemala: “[...] un territorio de alta productividad, debido a los valores de retorno (diferencia entre inversión y beneficio) que se presume tenían los recursos disponibles” (Verdesio 67). Ello solamente es posible en esta nueva mentalidad que el criollo adquirirá a lo largo de los siglos xVII y xVIII en su vínculo con el territorio (su patria) en la que tuvo la dicha de nacer; su elogio posibilita, entonces, el enaltecimiento de sus diferencias con respecto a la Metrópoli.

\footnotetext{
Revista Iberoamericana, Vol. LXXVIII, Núm. 241, Octubre-Diciembre 2012, 769-781 


\section{Obras Citadas}

Calvo, Nancy y Rodolfo Pastore. "De viajeros y periodismo ilustrado. Los aportes del naturalista Tadeo Haenke en el Telégrafo Mercantil del Río de la Plata(1801-1802)”. Dieciocho 28/2 (2005): 23-46.

Chen Sham, Jorge. "Patrimoine discursif et mémoire dans la construction du principe d’autorité: La Recordación florida de Francisco Antonio de Fuentes y Guzmán”. Europe XVI-XVII 11 (2007): 125-40.

Cortés, Hernán. Cartas de la conquista de México. Madrid: SARPE, 1985.

Cross, Edmond. Théorie et Pratique Sociocritiques. Montpellier: CERS, 1983.

Dorca, Toni. Volverás a la región: El cronotopo idílico en la novela española del siglo XIX. Madrid: Iberoamericana, 2004.

Ewalt, Margaret. "Crossing Over: Nations and Naturalist in El Orinoco Ilustrado. Reading and Writing the Book of Orinoco Secrets”. Dieciocho 29/1 (2006): 7-31.

Flor, Fernando de la. "Arcadia y Edad de Oro en la configuración de la bucólica dieciochesca”. Anales de Literatura Española 2 (1983): 133-153.

Fuentes y Guzmán, Francisco Antonio de. Recordación florida: discurso historial y demostración natural, material, militar y político de Reyno de Guatemala. Carmelo Sáenz de Santa María, ed. Guatemala: Sociedad de Geografía e Historia, 1932.

González-Stephan, Beatriz. "Del catálogo a la escritura historiadora: Archivo imperial y afirmación criolla”. Jorge Chen Sham, ed. “Actas del simposio hacia la comprensión del 98: representaciones finiseculares en España e Hispanoamérica”. San José: Centro Cultural Español-Editorial de la Universidad de Costa Rica, 2001. 35-54.

Jovellanos, Gaspar Melchor de. Obras publicadas e inéditas. Tomo 2. Madrid: Real Academia Española, 1952.

Kaempfer, Álvaro. “A la modernidad por la agricultura: Ética rural y utopía campesina en Domingos Vandelli y Gaspar Melchor de Jovellanos”. Dieciocho 30/2 (2007): 339-63.

Lafarga, Francisco. “Territorios de lo exótico en las letras españolas del s. XVIII”. Anales de Literatura Española 10 (1994): 173-92.

Maravall, JoséAntonio. “Dos términos en la vida económica: La evolución de los vocablos ‘industria’ y ‘trabajo’”. Cuadernos Hispanoamericanos 280-282 (1973): 633-685. “Espíritu burgués en la Ilustración española”. Hispanic Review 47/3 (1979): 291-325.

Martínez Peláez, Severo. La patria del criollo: ensayo de interpretación de la realidad colonial guatemalteca. 2 ed. San José: EDUCA, 1973.

Méndez, Francisco Alejandro. "Dos cronistas coloniales que reflejan al indio a través de su particular espejo”. Cultura de Guatemala 26/1 (2005): 33-42.

\footnotetext{
Revista Iberoamericana, Vol. LXXVIII, Núm. 241, Octubre-Diciembre 2012, 769-781 ISSN 0034-9631 (Impreso) ISSN 2154-4794 (Electrónico)
} 
Merriman, Stephanie. “Civilización y barbarie: Prescott como lector de Cortés”. La historia en la literatura iberoamericana: Memorias del XXVI Congreso del Instituto Internacional de Literatura Iberoamericana. Raquel Chang-Rodríguez y Gabriella de Beer, eds. Hanover: Ediciones del Norte, 1989. 87-96.

Nieto Olarte, Mauricio. Remedios para el imperio: Historia natural y la apropiación del nuevo mundo. 2 ed. Bogotá: Editorial Uniandes, 2006.

Rodríguez Cascante, Francisco. "La historia natural como discurso de la abundancia en la Recordación florida, de Fuentes y Guzmán”. Cultura de Guatemala 25/2 (2004): 65-74.

Verdesio, Gustavo. "Hacia la descolonización de la mirada geográfica: Las prácticas territoriales indígenas en la 'prehistoria' de la ribera norte del Río de la Plata”. Revista Iberoamericana 65/186 (1999): 59-80.

Revista Iberoamericana, Vol. LXXVIII, Núm. 241, Octubre-Diciembre 2012, 769-781 ISSN 0034-9631 (Impreso) ISSN 2154-4794 (Electrónico) 
